\title{
Memória us esquecimento: análise do processo de formulação da Lei de Acesso à Informação
}

\author{
Memory vs oblivion: analysis of the Law on Access to Public \\ Information formulation process
}

\section{Alessandra Guimarães Soares}

\section{Resumo}

O objetivo deste trabalho é analisar o processo político que levou as mudanças na Lei de Acesso à Informação Pública que permitiram a abertura dos arquivos do período de exceçáo e, consequentemente, serviram para viabilizar os trabalhos da Comissão Nacional da Verdade (CNV). A análise, realizada a partir do binômio memória vs esquecimento, traz os embates travados sobre esse tema no Congresso Nacional pós-Constituição de 1988 até o ano de 2011, momento de criação da CNV e da edição da última alteração da Lei de Acesso à Informação. O referencial teórico metodológico empregado foi o do advocacy coalition framework.

\section{Palavras-chave}

Lei de Acesso à Informaçáo; Congresso Nacional; Advocacy Coalition Framework.

\begin{abstract}
This paper analyzes the political process that led the changes in the Law on Access to Public Information that allowed the opening of archives of the period of exception and, consequently, served to make feasible the work of the National Truth Comission (CNV). The analysis, based on the memory and oblivion binomial, brings the clashes to this topic in the National Congress after the Constitution of 1988 until 2011, when were created the CNV and the last amendment of the Law on Access to Information. The theoretical methodological reference used was the advocacy coalition framework.
\end{abstract}

\section{Keywords}

Law on Access to Information; National Congress; Advocacy Coalition Framework. 


\section{Introdução}

A busca pela verdade sobre os fatos ocorridos no período de exceção, pelo resgate da memória e pelo direito à justiça com a responsabilização dos agentes do Estado que praticaram crimes durante a ditadura é vista como condição necessária para a própria história republicana e consiste em um dos pilares do processo de consolidação democrática. Constituído de um longo processo de discussões políticas, esse embate, travado em diversas arenas sociais, teve a sua institucionalização com a edição de algumas leis, sendo as principais: a Lei no 12.528/2011 (BRASIL, 2011a), a qual criou a Comissão Nacional da Verdade (CNV), que tem como objetivo central examinar e esclarecer as graves violaçóes de direitos humanos praticadas no período compreendido entre 1946 a 1988; e a que deu nova redação da LAI - Lei de Acesso à Informação (Lei no 12.527/2011 - BRASIL, 2011b), permitindo a abertura dos arquivos da ditadura e, consequentemente, possibilitando a execução dos trabalhos da CNV.

Para Teles (2006), o sigilo relacionado aos fatos ocorridos durante o regime de repressão é prática recorrente desde o fim do regime militar de 1964. A Constituição Federal de 1988 estabelece em seu art. 5º inciso XXXIII, que os prazos para acesso à informação devem ser previstos em lei. $\mathrm{O}$ art. $37, \$ 3^{\circ}$, inciso II, desse mesmo diploma legal, complementa que o acesso aos registros e informações sobre atos do governo devem ser disciplinados e regulados por lei e, por fim, o art. $216, \S$ $2^{\circ}$ dispõe que compete a administração pública, mediante lei, gerir a documentação governamental e tomar providências para franquear sua consulta (BRASIL, 1988). Apesar dessa prescrição constitucional, ao longo de mais de duas décadas, o acesso a documentos públicos, principalmente os relacionados ao período ditatorial, foi resguardado por inúmeras restriçôes que somente foram transpostas com a edição da LAI no ano de 2011.

Assim, objetiva-se neste trabalho analisar o processo político que levou às mudanças na LAI que permitiram a abertura dos arquivos do período de exceção e, consequentemente, serviram para viabilizar os trabalhos da CNV. Para tanto, foi empregado o referencial teórico metodológico do Advocacy Coalition Framework (ACF). Desenvolvido por Sabatier (1988) no final da década de 1980 e aprimorado por Sabatier e Jenkins-Smith (1993 e 1999) e Sabatier e Weible (2007), nas décadas seguintes, esse modelo apresenta variáveis que permitem explicar os processos causais a partir dos fatores cognitivos, institucionais e do papel desempenhado pelos atores no processo político. A análise, realizada a partir do binômio memória vs esquecimento, traz os embates travados sobre esse tema a partir da legislação de 
acesso à informação produzida pós-Constituição de 1988 até o ano de 2011, momento de criação da CNV e da edição da última alteração da Lei de Acesso à Informação.

O texto está dividido em quatro tópicos. O primeiro apresenta de forma breve o referencial teórico metodológico do modelo do ACF. O segundo aborda a institucionalização da LAI. O terceiro é dedicado a abordar o processo político que levou a mudança no texto da LAI. Por fim, apresentam-se as considerações finais.

\section{Modelo de coalizão de defesa}

O destaque dado para abordagens voltadas ao papel das ideias, linguagem e argumentação na produção de políticas (FISHER e FORESTER, 1993) tem recebido atenção da literatura da área de Políticas Públicas por apresentar elementos relacionados aos aspectos cognitivos, que permitem trazer um olhar diferenciado para compreensão do complexo processo do "fazer" política pública. Dentre as perspectivas teóricas que buscam dar ênfase ao papel das ideias e do conhecimento no processo das políticas, sobressai o modelo do advocacy coalition framework $(\mathrm{ACF})^{1}$. Desde a sua versão original, o modelo vem sendo aprimorado pelos autores através da análise da sua aplicação empírica em diversos estudos de caso e também de consideraçôes de críticos que utilizaram o modelo enquanto referencial teórico (SABATIER e JENKINS-SMITH, 1999).

A ideia do modelo do ACF é contemplar todas as fases do ciclo de políticas públicas (agenda, formulação, implementação e avaliação) e focar em mudanças políticas. Para isso, o quadro apresenta a seguinte estrutura: subsistema de política como principal unidade de análise; perspectiva de longo prazo, uma ou mais décadas, para compreensão do subsistema; a agregação dos atores em grupos, chamados coalizões e o desenho da política como tradução das crenças desses grupos. Esses pressupostos permitem, aos estudiosos, compreender o processo político, em especial, a formação e manutenção dessas coalizões e a mudança de política.

O subsistema pode ser entendido como o conjunto de atores individuais ou coletivos, governamentais e não governamentais, os quais, preocupados com uma questão ou problema político (educação, segurança, direitos humanos etc.), dirigem

\footnotetext{
${ }^{1}$ De acordo com John (1988 e 2003) são três as abordagens teóricas que dão ênfase ao papel das ideias e do conhecimento no processo das políticas, são elas: a abordagem dos múltiplos fluxos de John Kingdon (2003), o modelo de coalizóes de defesa de Sabatier e Jenkins-Smith (1993) e o do equilíbrio pontuado de Baumgartner e Jones (1993).
} 
seus esforços para uma determinada área de política pública, atuando de forma coordenada com objetivo de transformar seus posicionamentos em programas e políticas governamentais (SABATIER e JENKINS-SMITH, 1993). No subsistema, esses diversos atores governamentais (de todos os níveis) e não governamentais (jornalistas, pesquisadores, analistas políticos, entre outros) relacionam e tencionamse constantemente em uma relação em longo prazo, geralmente uma década ou mais, na qual são guiados por um sistema de crenças e prioridades que buscam a todo o momento traduzir em políticas públicas (SABATIER, 1988).

Para os teóricos do ACF, a regra fundamental para identificar um subsistema é recortá-lo no âmbito material (por exemplo, a política de água) e territorial, que pode ser uma área geográfica (por exemplo, Bacia de água do Rio São Francisco), ou a esfera, se a nível federal, estadual ou municipal (SABATIER e JENKINS-SMITH, 1993; SABATIER e ZAFONTE 2004; SABATIER e WEIBLE, 2007). No subsistema, os atores ${ }^{2}$ (governamentais e não governamentais) agregam-se a partir de suas convicções, opiniōes, ideias e objetivos, formando grupos, denominados pelo ACF, de "coalizões de defesa", na tentativa de tentar traduzir suas ideias em políticas públicas (SABATIER e WEIBLE, 2007). Neste trabalho, o recorte do subsistema foi realizado no âmbito material a partir da análise das discussões acerca da LAI, que permitiu a abertura dos arquivos do período de repressão.

Já a coalizão de defesa é definida por Sabatier (1988) como sendo o conjunto de pessoas das mais diversas posições (representantes eleitos, funcionários públicos, líderes de grupos de interesse, pesquisadores, intelectuais, empresários, representantes da sociedade civil, entre outros), que compartilham um determinado sistema de crenças (valores, ideias, objetivos políticos, formas de perceber problemas políticos, pressupostos causais, etc.) e que demonstram um grau não trivial de atividades coordenadas ao longo do tempo.

O ACF assume, dessa forma, que os atores têm crenças ${ }^{3}$ políticas fortes e que buscam meios eficazes que permitam transformar suas crenças em políticas reais (programas de governos, leis, etc.). Na perspectiva teórica do ACF, as crenças políticas balizam não só a coordenação, mas também o conflito entre os atores que

\footnotetext{
${ }^{2} \mathrm{O}$ modelo do ACF pressupóe que um subsistema contém um conjunto amplo e diverso de atores e, por isso, para mapeá-los e verificar sua atuação no processo decisório político, considera aqueles que de alguma forma desempenham um papel, percebido como relevante na condução das ideias relacionadas à formulação e implementação das políticas (SABATIER e JENKINS-SMITH, 1993).

${ }^{3} \mathrm{Na}$ perspectiva do modelo, são as crenças, e não os interesses comuns partilhados pelos atores, que os unem em coalizóes.
} 
participam do processo decisório. Regra geral, os autores que aplicam o ACF tendem a mapear as crenças a partir das disputas políticas sobre o tema objeto de pesquisa (WEIBLE et al., 2011), sem, necessariamente, fazer a distinção de crenças nos três núcleos (deep core, policy core e instrumental aspects) proposta pelo modelo.

Neste trabalho, optou-se por mapear as crenças dos atores a partir das disputas políticas sobre o acesso à informação pública, com enfoque para a questão relacionada à abertura dos arquivos do período da ditadura militar. Seguindo a lógica do modelo do ACF, no qual tanto as políticas públicas, quanto os programas governamentais, espelham o predomínio de determinado sistema de crenças (SABATIER e JENKINS-SMITH, 1999), optou-se por analisar o processo decisório em torno da legislação de acesso à informação que dá suporte ao trabalho da Comissão Nacional da Verdade (CNV). Para tanto, analisou-se a legislação de acesso à informação produzida pós-Constituição de 1988 até o ano de $2011^{4}$, data da criação da CNV.

Nessa análise, verificou-se que as discussões sobre o acesso à informação foram margeadas por dois grupos antagônicos. Um que buscava a abertura irrestrita dos arquivos públicos, com objetivo de ter acesso aos arquivos produzidos, sobretudo, pelos órgãos de repressão, durante os anos de chumbo e o outro grupo contrário a sua abertura ${ }^{6}$, sendo suas crenças sobre esse tema as delimitadas abaixo no Quadro 1.

\footnotetext{
${ }^{4}$ Foram analisadas as discussóes travadas no Congresso Nacional, Câmara dos Deputados e Senado Federal, sobre esse tema e as seguintes legislaçóes: Leis no 8.159/1991 (BRASIL, 1991) e no 12.527/2011 (BRASIL, 2011); Decretos no 2.134/1997 (BRASIL, 1997) e no 5.584/2005 (BRASIL, 2005) e Projetos de lei no 219/2003 (BRASIL, 2003) e no 5.228/2009 (BRASIL, 2009).

${ }^{5}$ Geralmente nesse grupo encontram-se pessoas que sofreram violaçóes de direitos humanos durante o período de repressão, ou que tiveram familiares mortos e desaparecidos nesse período, militantes de direitos humanos e algumas ONGs e entidades da sociedade civil como: o Grupo Tortura Nunca Mais (GTNM), Associação Nacional de História (ANPUH), Associação Brasileira de Jornalismo (ABRAJI), Conselho Nacional de Arquivos (CONARQ), etc.

${ }^{6}$ Esse grupo era, geralmente, formado por militares ou por apoiadores do regime. Assim, quando o texto referir-se aos militares, na realidade, estão englobados apenas os favoráveis ao sigilo dos documentos.
} 
Quadro 1 - Crenças políticas

\begin{tabular}{|c|c|}
\hline Acesso amplo & Inacessibilidade do acesso \\
\hline Acesso amplo aos documentos da ditadura. & $\begin{array}{l}\text { Inacessibilidade aos documentos da } \\
\text { ditadura. }\end{array}$ \\
\hline $\begin{array}{l}\text { Abertura em nome da transparência } \\
\text { democrática. }\end{array}$ & $\begin{array}{l}\text { Sigilo eterno em nome da segurança } \\
\text { nacional. }\end{array}$ \\
\hline $\begin{array}{l}\text { Direito à privacidade náo se sobrepóe a } \\
\text { abertura. }{ }^{7}\end{array}$ & $\begin{array}{l}\text { Preservaçáo dos documentos para garantir } \\
\text { o direito à privacidade, sob argumento de } \\
\text { que sua abertura poderia trazer prejuízos } \\
\text { aos opositores do regime. }\end{array}$ \\
\hline Reconstrução da história. & Manutenção do esquecimento. \\
\hline $\begin{array}{l}\text { Abertura auxiliaria na responsabilização dos } \\
\text { torturadores (Tortura é crime contra a } \\
\text { humanidade e crime de desaparecimento } \\
\text { forçado não prescreve). }\end{array}$ & $\begin{array}{l}\text { Restriçáo ao acesso aos documentos para } \\
\text { evitar revanchismo (conciliaçáo pactuada } \\
\text { na Lei da Anistia prevalece). }\end{array}$ \\
\hline
\end{tabular}

Fonte: Dados compilados pela autora.

\section{Institucionalização da Lei de Acesso à Informação}

A primeira previsão legislativa para garantir o acesso à informação, previsto constitucionalmente, adveio com a Lei no 8.159 de 08 de janeiro de 1991 (BRASIL, 1991) (conhecida como Lei de Arquivos) ${ }^{8}$. Porém, o texto dessa norma buscou garantir muito mais o sigilo do que o acesso aos documentos e informaçôes, além de ter deixado algumas lacunas que posteriormente facilitaram a edição de diversos decretos questionáveis.

A publicação dessa legislação (Lei no 8.159/1991) gerou inúmeras críticas dos militares, que pretendiam dar nova redação a essa norma. Para tanto, à época, a Secretaria de Assuntos Estratégicos (SAE) ${ }^{9}$ elaborou projeto em que os prazos de

\footnotetext{
${ }^{7}$ Aqui existem duas crenças: os que entendem que o direito à vida privada não se sobrepõe à abertura dos documentos, e aqueles que entendem que esse direito pode restringir o acesso aos documentos, sendo permitido apenas mediante autorização.

${ }^{8}$ De acordo com Fico (2012) arquivistas, profissionais e instituiçóes acadêmicas interessados na criação de regras justas, bem como o CONARQ, participaram da elaboração das normas da Lei de Arquivos. ${ }^{9}$ A SAE é antecessora da Agência Brasileira de Inteligência (ABIN) e sucessora do Serviço Nacional de Informaçôes (SNI).
} 
sigilo começariam a contar do momento da classificação (categorização em secretos, ultrassecretos, etc.) dos documentos e informações, e não da sua produção. Porém, não obteve êxito nesse projeto e essa lei foi mantida (ATO..., 2003).

Para regulamentar a Lei de Arquivos, em 1997, o governo FHC editou o Decreto $\mathrm{n}^{\circ} 2.134$ de 24 de janeiro (BRASIL, 1997), limitando o prazo de sigilo dos documentos ultrassecretos para trinta anos, prorrogável por igual período, e conferiu aos chefes dos poderes Executivo, Legislativo e Judiciário a competência para classificação da documentação. Esse ato gerou nova reação da ala militar favorável ao sigilo. A queixa era em relação aos prazos e à competência para classificaçáo da documentação. $\mathrm{Na}$ ocasião, a Subsecretaria de Inteligência da Presidência queria que também fosse conferido poder às Forças Armadas para categorizar os documentos ultrassecretos (ATO..., 2003). No entanto, o decreto foi mantido, conferindo suporte legal para o acesso a documentos sigilosos, especialmente os relativos ao período de repressão (FICO, 2012). Para esse autor, ambos, a lei de 1991 e o decreto de $1997^{10}$, tinham caráter democrático e viabilizaram a instalação e funcionamento de comissóes de acesso "em vários órgãos da administração pública do país" (FICO, 2012, p. 55).

No final do ano de 2002, a ala militar contrária a abertura dos documentos obteve êxito com a aprovação do Decreto no 4.553/2002 (BRASIL, 2002). Para a pesquisadora da Fundação Getúlio Vargas, Célia Costa, a edição dessa norma, ao apagar das luzes do segundo governo de Fernando Henrique Cardoso, decorreu de pressôes: "Acho que FHC foi pressionado novamente pela ala militar, que não engoliu o decreto de 1997 (...) No varejo ainda há influência militar (ATO..., 2003)". Na ocasião, por meio de um ex-assessor, o ministro da Casa Civil, Pedro Parente, declarou que "o decreto foi gerado integralmente no GSI [Gabinete de Segurança Institucional] (ATO..., 2003)”. Ou seja, apesar desse tipo de decreto (ato da administração que visa regulamentar leis) ser um ato inerente aos chefes do poder executivo (presidente da República, governadores e prefeitos), ficou claro, nesse caso, que quem realmente elaborou o texto foi um representante das forças armadas para assegurar a inacessibilidade aos arquivos militares e, com isso, obstaculizar não só a solução de diversos casos de mortes e desaparecimentos ocorridos durante o regime de repressão, mas também prejudicar o processo de resgate da memória social e política do Brasil.

${ }^{10}$ O CONARQ teve papel central para elaboração do texto do decreto no 2.134/1997. 
Como se verifica, o pedido da ala militar foi atendido. O texto que saiu do Gabinete de Segurança Institucional (GSI) da Presidência da República, comandado à época pelo general Alberto Cardoso, trouxe diversas alteraçóes favoráveis à ala militar, dentre elas, o aumento no prazo de sigilo de 30 para 50 anos, com a possibilidade de prorrogação infinita, e a extensão da competência para classificação dos documentos aos Comandantes da Marinha, Exército e Aeronáutica (MAGALHÃES, 2003). O artigo $6^{\circ}$ desse decreto, ao mesmo tempo em que, retirou a competência dos chefes dos Legislativo e Judiciário, estendeu ao Vice Presidente da República, Ministros de Estado e aos Comandantes da Marinha, Exército e Aeronáutica (MAGALHÂES, 2003) a responsabilidade pela classificação dos documentos.

Como se observa, durante o governo FHC houve avanços e retrocessos na LAI. Em um primeiro momento, o decreto editado em 1997 se aproximou mais dos ideais do grupo que queria o acesso amplo aos documentos. Contudo, ante a insatisfação dos militares contrários à abertura dos arquivos e a influência exercida por eles junto ao governo, com um membro (autoridade legal na GSI) na estrutura governamental, com poder de transformar suas ideias em política, permitiu que esse cenário se alterasse no ano de 2002 (data de edição do decreto) e suas crenças prevalecessem. Vale destacar que, no modelo do ACF, atores em posição estratégica dentro do governo são vistos como membros potenciais para as coalizóes, já que a característica da coalizão dominante é justamente essa, possuir membro(s) com autoridade institucional em diferentes níveis do governo com capacidade para tomar decisôes políticas (SABATIER e WEIBLE, 2007).

Outro ponto relevante que deve ser considerado, nesse caso, é a concentração de poder nas mãos do chefe do Poder Executivo, já que a mudança favorecendo o grupo contrário a abertura dos documentos se deu por meio de um decreto de competência desse poder. A concentração de poderes nas mãos do Executivo é uma variável entendida como fundamental por alguns autores, que aplicaram o ACF em suas pesquisas, para explicar a mudança política (VIANA, 2011; VICENTE, 2012; OLIVEIRA, 2012). Aqui, é preciso levar em consideração que o decreto também continha normas que permitiam o sigilo sobre documentos produzidos durante o governo FHC. Ou seja, o próprio Executivo tinha seus interesses ao editar essa legislação, que igualmente lhe beneficiava.

Não sem razão, a edição dessa norma gerou reaçóes de diversos setores, entidades como Grupo Tortura Nunca Mais (GTNM), Associação Nacional de História (ANPUH), Associação Brasileira de Jornalismo (ABRAJI), Conselho 
Nacional de Arquivos (CONARQ), pesquisadores, juristas, militantes de direitos humanos, entre outros, repudiaram, por meio de moçôes, essa atitude do governo FHC de, no final do seu mandato, inibir acesso a documentos sigilosos da administração pública, assim como o fato de Lula, então eleito presidente, não revogar o decreto. $\mathrm{Na}$ ocasião, Célia Costa, representante do Centro de Pesquisa e Documentação de História Contemporânea do Brasil da Fundação Getúlio Vargas (CPDOC), declarou: "O governo não só não revogou, como tem feito uso do 4.553. A comissão interministerial que investiga a Guerrilha do Araguaia tem como parâmetro os critérios de sigilo do decreto de FHC (PROJETO..., 2004)”. De acordo com Joffily:

O fato de o texto do decreto ter sido formulado por um general, então comandante do Gabinete de Segurança Institucional, e de não ter sido anulado pelo presidente de esquerda Luiz Inácio Lula da Silva, mostra o delicado equilíbrio sobre o qual repousa a transição para a democracia da sociedade brasileira (JOFFILY, 2012, p. 136).

Outra queixa era que os documentos secretos do golpe de 1964 poderiam ser liberados em 2004, após quarenta anos de sua produção. Porém, com a nova regulamentação, esse prazo se estendeu até 2024, correndo-se o risco de serem prorrogados indefinidamente (MAGALHÁES, 2003). Mais um ponto controvertido foi quanto à constitucionalidade do decreto. Segundo o constitucionalista Fábio Comparato, "[O decreto] evidentemente está contrariando a lei (MAGALHÁES, 2003)". A Lei de Arquivos dispóe em seu art. 23, e parágrafos, o prazo máximo de restrição de documentos sigilosos de sessenta anos, no entanto, o decreto editado por FHC contraria essa lei, ao fixar prazo superior ao que está nela previsto. À época, o constitucionalista Celso Bastos (MAGALHÁES, 2003) declarou que esse decreto era inconstitucional, uma "aberração", já que pelo princípio da legalidade não se admite que o Poder Executivo extrapole sua competência, alterando, criando ou extinguindo direitos via decreto e, com isso, invadindo competência adstrita ao Legislativo.

Ainda, a interpretação do art. 5\%, II da CF/88 estabelece que "Ninguém será obrigado a fazer ou deixar de fazer alguma coisa senão em virtude de lei", isto é, o prazo a ser observado deveria ser o constante no $\$ 2^{\circ}$ do artigo 23 da Lei $n^{\circ}$ $8.159 / 1991$, prazo máximo (com a prorrogação) de sessenta anos. Já o Decreto no $4.553 / 2002$, como se observa em seu artigo $7^{\circ}$, extrapola os limites da legislação que 
deveria regulamentar ao estabelecer prazo de cinquenta anos, com possibilidade de renovação indefinidamente.

Diante da patente inconstitucionalidade do decreto, a deputada Alice Portugal (PCdoB) apresentou, em março de 2003, projeto de decreto legislativo (PDC 11/2003 - PORTUGAL, 2003) de Sustação de Atos Normativos do Poder Executivo. $\mathrm{Na}$ justificativa do PDC, pontuou que o decreto exorbitava o disposto na legislação de 1991 e feria o princípio da transparência, norteador dos atos da Administração Pública, tornando inacessíveis documentos que auxiliariam na construção da memória nacional e no esclarecimento de fatos históricos, como os ocorridos durante o período de repressão. Contudo, na Comissão de Constituição e Justiça (CCJ) a matéria foi considerada prejudicada pelo relator em razão da edição do Decreto no 5.301 de 09 de dezembro de 2004 (BRASIL, 2004), que alterou a redação desse artigo e reduziu os prazos de sigilo, retornando ao tempo máximo fixado na Lei de Arquivos de 1991, isto é, 30 anos prorrogável por igual período.

Com a edição desse decreto, foi criada a Comissão de Averiguação e Análise de Informações Sigilosas, constituída no âmbito da Casa Civil da Presidência da República, com objetivo de decidir se os documentos e informaçôes sigilosas estavam cobertos ou não pela exceção estabelecida na parte final do art. $5^{\circ}$, inciso XXXIII da Constituição Federal de 1988 que estabelece "ressalvadas aquelas cujo sigilo seja imprescindível à segurança da sociedade e do Estado”. Para Zaverucha (2005), deixar a decisão sobre quais documentos serão considerados sigilosos, com base nesse dispositivo constitucional e nas mãos de diferentes órgãos governamentais ${ }^{11}$, "abriu no Decreto a brecha para que documentos possam ficar eternamente sigilosos. Os papéis caem em um limbo jurídico e de lá sairão somente se essa Comissão, e não a sociedade, assim desejar" (ZAVERUCHA, 2005, p. 118). Se o decreto criou esse limbo, a conversão da medida provisória 228/2004, na Lei 11.111 de 05 de maio de 2005 (BRASIL, 2005), serviu para coroá-lo, ao regulamentar o disposto na parte final do inciso XXXIII do art. $5^{\circ} \mathrm{da} \mathrm{CF} / 88$ e instituir em definitivo a Comissão de Averiguação e Análise de Informações Sigilosas, bem como suas atribuições.

\section{Manutenção do sigilo: Lei $n^{\circ} 11.111 / 2005$}

\footnotetext{
${ }^{11}$ A Comissão de Averiguação é composta por ministros da Casa Civil, da Justiça, da Defesa e das Relaçóes Exteriores, chefe de Gabinete de Segurança, Advogado-Geral da União e do Secretário de Direitos Humanos da Presidência da República ( $\$ 1^{\circ}$ do art. 4º, Decreto $n^{\circ}$ 5.301/2004 - (BRASIL, 2004).
} 
Na prática, a Lei no 11.111/2005 manteve as lacunas deixadas pelo decreto de 2004, já que possibilitou a manutenção do sigilo de certos documentos por prazo indeterminado, estabelecendo que compete a uma Comissão composta por representantes de diversos ministérios, incluindo o da defesa, manifestar-se sobre o acesso à documentação. Embora os prazos estejam em consonância com a Lei de Arquivos e a expressão "poderá ser renovado indefinidamente" tenha sido suprimida da Lei, no final tudo permaneceu igual.

Segundo Silva e Frota (2009), a edição dessa lei serviu para “apagar incêndios" dos dois lados, acalmou os ânimos da sociedade civil, ao retomar os prazos da Lei de Arquivos, e atendeu os militares e outros interessados na manutenção do sigilo. De fato, em declaração, à época, do ministro da Secretaria de Direitos humanos da Presidência da República (SDH/PR), Nilmário Miranda, antes mesmo da edição do decreto de 2004, ficou clara a cautela em relação a esse tema e que a ideia era avançar no resgate histórico e ao mesmo tempo primar pela proteção do sigilo do Estado: "O governo vai reexaminar o decreto [de FHC], mas dentro dos parâmetros já colocados pelo presidente, com a cautela de não provocar ressentimentos, crises políticas nem militares (...). Podemos avançar de forma tranquila, mas isso depende de muitos arranjos, muitos acordos (KRAKOKICS e ALENCAR, 2004)".

Como se observa, a mudança de governo FHC para o Lula, que o modelo do ACF denomina de choque externo, não trouxe alteração substantiva na legislação, sobretudo em relação à abertura dos documentos da ditadura militar. Ao contrário, Lula, embora pressionado desde o início do seu governo para mudar o Decreto presidencial de 2002, o fez apenas em 2005 em um intuito claro, como já demonstrado, de acalmar os ânimos dos dois grupos em disputa. Porém, ao final, como já visto, o conteúdo das normas produzidas mostrou-se muito mais favorável aos anseios daqueles favoráveis ao sigilo, demonstrando o poder que esse grupo ainda mantinha sobre as decisões políticas do governo.

Em novembro de 2005 foi editado o Decreto no 5.584 (BRASIL, 2005), o qual determinou o recolhimento ao Arquivo Nacional dos documentos sigilosos de três órgãos de investigação política do período de repressão: Serviço Nacional de Informação (SNI), Conselho de Segurança Nacional (CSN) e Comissão Geral de Investigaçóes (CGI). Nessa ocasiáo, pensou-se que esse decreto auxiliaria o acesso aos documentos, contudo, a transferência desses arquivos não mudou em nada o sigilo que recaía sobre esses documentos. Esse ato foi visto pelas entidades de defesa dos 
direitos humanos como mais um gesto simbólico, um "faz de conta", de acordo com o GTNM-RJ (MAGALHÃES, 2006), uma medida paliativa para atender as exigências do Comitê de Direitos Humanos da ONU, que criticou o país em sua $85^{\mathrm{a}}$ reuniáo, por ainda manter documentos em sigilo, e considerou insuficiente como forma de responsabilização apenas o pagamento das indenizações às vítimas e familiares da ditadura (OLIVEIRA, 2005). Em que pesem as críticas a esse decreto, ele mostrou-se fundamental para a preservaçáo dos documentos.

Contrastando com os esforços empreendidos para impor limites ao acesso aos documentos sigilosos, o governo federal, em setembro de 2009, juntamente com a $\mathrm{SDH} / \mathrm{PR}$, lançou uma campanha publicitária fazendo um apelo à sociedade para obtenção de documentos produzidos durante a ditadura militar, especialmente aqueles que pudessem auxiliar na localização de desaparecidos políticos. Essa ação resultou na criação do Centro de Referência das Lutas Políticas no Brasil (19641985) - Memórias Reveladas, coordenado pelo Arquivo Nacional. Esse projeto da Casa Civil da Presidência da República foi idealizado pela ministra, à época, Dilma Rousseff e pelo então ministro Paulo Vannuchi (SDH), ambos ex-presos políticos.

O ministro Vannuchi sempre se mostrou favorável não apenas ao amplo acesso ao acervo documental sobre a ditadura, mas também em relação à punição dos torturadores que agiram em nome do Estado. Mostra disso é que em 2008 o ministro relatou conversa entre ele e o presidente Lula, na qual pedia que fosse dada uma solução para a questão dos mortos e desaparecidos políticos, especialmente no que tange a punição dos torturadores: "O senhor não pode terminar oito anos [de mandato] sem ter uma solução para esse tema. Pode não ser a ideal, pode não ser a desejada por todos nós, mas que seja pelo menos uma solução" (FARIA, 2008).

Segundo Vanucchi, a tortura é crime contra a humanidade, portanto, não abarcada pela Lei da Anistia. Nessa ocasião, a ministra Dilma Rousseff afirmou que: "Eu, pessoalmente, como cidadã e indivíduo, acho que o crime de tortura é imprescritível” (ALENCAR, 2008).

Paralelamente tramitava na Câmara dos Deputados, desde o ano de 2003, um projeto de lei 219/2003 (BRASIL, 2003), com vistas a regulamentar a prestação de informações detidas pelos órgãos da Administração Pública. Esse projeto deu origem à Lei no 12.527 de 18 de novembro de 2011(BRASIL, 2011), conhecida como Lei de Acesso à Informação (LAI). Entre outros projetos de lei, foi apensado ao PL 
219/2003 (LOPES, 2003) o PL 5.228/2009 (PODER EXECUTIVO, 2009) de autoria do Poder Executivo ${ }^{12}$.

Cabe destacar que entre os autores desse projeto (PL 5.228/2009) quatro ministros eram ex-presos políticos: Dilma Rousseff, Tarso Genro, Paulo Vannuchi e Franklin de Souza Martins, os quais tinham como premissa, dado ao histórico de perseguidos políticos, dar amplo acesso aos documentos da Administração Pública e restringir ao máximo os casos passíveis de sigilo. Prova disso é o texto do projeto impor uma série de limitaçôes à possibilidade de sigilo e penalidades para os militares e agentes públicos que se recusassem a fornecer informaçôes. Também vedou, em clara referência ao período de repressão política, a restrição de acesso aos documentos relativos às condutas praticadas por agentes públicos ou a seu mando, relacionadas à violação de direitos humanos. Ainda, o texto estabeleceu que o direito à vida privada não poderia ser invocado nas açôes voltadas à recuperação de fatos históricos de maior relevância.

Importa acrescentar que o apensamento desse projeto ao PL 219/2003, imprimiu força à sua discussão, o regime de tramitação foi modificado para dar urgência e o texto do PL de 2003 foi robustecido, passando de vinte e um artigos para quarenta. No modelo do ACF, atores em posição estratégica dentro do governo são vistos como membros potenciais para as coalizóes em disputa, já que a característica da coalizão dominante é justamente essa, possuir membro(s) com autoridade institucional em diferentes níveis do governo com capacidade para tomar decisões políticas (SABATIER e WEIBLE, 2007). Nesse caso, os autores do PL 219/2003 tinham posição de destaque dentro da estrutura governamental, o que imprimiu celeridade a discussão da matéria. Quando da votação da deliberação da matéria, o deputado Reginaldo Lopes, autor do PL 219/2003 declarou: "Há 6 anos projeto sobre a matéria tramita nesta Casa - e foi essa proposição que criou as condiçôes políticas para que esse instrumento fosse aprovado" (BRASIL, DCD, 2010, p. 14.793).

A preocupação que norteou a discussão dessa matéria na Câmara dos Deputados (Comissão Mista) era quanto ao artigo que permitia a desclassificação

\footnotetext{
12 Mensagem (MSC) 316/2009. Seu texto foi elaborado pelos seguintes ministros: Dilma Rousseff (Casa Civil), Tarso Fernando Herz Genro (Justiça), Celso Luiz Nunes Amorim (Relaçóes Exteriores), Nelson Azevedo Jobim (Defesa), Paulo Vannuchi (SEDH-PR), Jorge Armando Félix (GSI), Franklin de Souza Martins (Comunicação Social) e José Antônio Dias Toffoli (Advocacia Geral da União) e Jorge Hage (Controladoria Geral da União)
} 
automática dos documentos sigilosos, assim que atingido o prazo máximo, incluindo a prorrogação. A sugestão de alguns deputados era a desclassificação ocorrer apenas após provocação a uma Comissão Mista (que seria criada com essa finalidade), um dos argumentos utilizados era o da proteção da vida privada, já que os documentos pertinentes ao período de repressão política, poderiam ser prejudiciais tanto para as vítimas do período, quanto para os que atuaram em nome do Estado (BRASIL, DSF, 2010, p. 14.812).

Quando essa matéria debatida no PL 219/2003 foi levada ao Senado Federal, foram realizadas apenas alteraçôes redacionais na CCJ. Porém, na Comissão de Relações Exteriores e Defesa (CRED), foram apresentadas vinte (20) emendas. O relator da matéria foi o senador Fernando Collor de Mello, do Partido Trabalhista Brasileiro (PTB), que defendeu a restrição dos documentos, nos moldes dos decretos anteriores e mostrou-se totalmente contrário a proposta de divulgação de dados na internet. As sugestôes nessa comissão retomavam vários artigos restritivos dos antigos decretos de 2002 e 2005, em especial os prazos e as categorias de classificação dos documentos (BRASIL, DSF, 2010, p. 43.751). O substitutivo da Comissão de Relações Exteriores e Defesa (CRED) foi rejeitado.

Em maio de 2010, foi feito pedido de urgência e a matéria foi levada para aprovação em plenário. No dia 25 de outubro de 2010, o PL 219/2003 foi aprovado com pequenas alteraçóes na redação e, em 18 de novembro de 2011, foi editada a Lei $\mathrm{n}^{\mathrm{o}} 12.527 / 2011$. Nessa sessão também foi aprovado o requerimento de urgência para votação do projeto de lei para criação da Comissão Nacional da Verdade, no âmbito da Casa Civil da Presidência da República.

Joffily (2012), ao analisar os debates que antecederam a aprovação da Lei de Acesso à Informação, verificou que a tônica das ideias restringiu-se ao tema do sigilo eterno em nome da segurança nacional. A questão relacionada à proteção da vida privada foi pouco debatida. Segundo essa autora, apenas os que apoiam o sigilo eterno dos documentos ultrassecretos utilizam como justificativa o argumento do direito à vida privada. Joffily traz uma declaração de 2004 do general Jorge Armando Félix (ministro do GSI, à época) para corroborar que permanecia o discurso dos militares ativos durante a ditadura, isto é, forjado como sendo em defesa das vítimas do período: "Trata-se de defender o sigilo com argumentos que, aparentemente levantados para proteger as vítimas, servem para difamá-las" (JOFFILY, 2012, p. 141).

O amplo acesso aos documentos e informaçóes trata-se de uma demanda antiga das entidades de ex-perseguidos políticos e seus familiares, sendo a defesa do 
direito à privacidade, no máximo, considerada como uma restrição à abertura dos prontuários públicos das vítimas do período de repressão e não para manutenção do sigilo eterno. Ou seja, o direito à vida privada confere competência às vítimas para permitir ou não a livre consulta a seus dossiês pessoais, o que pode ser feito, como é o caso do Arquivo Estadual de São Paulo, por meio de uma assinatura a um termo de responsabilidade, quanto à propagação das informaçôes. De acordo com Joffily (2012), nos arquivos estaduais, por exemplo, o amplo acesso ao acervo dos "anos de chumbo" é regra e não exceção.

Em que pese esses argumentos, a assunçáo pública ou privada desse discurso, na sua gênese, está a privacidade. Porém, pode-se dizer que, diferentemente do discurso dos militares que usavam o direito à vida privada como forma de justificar a manutenção do sigilo, tanto o governo, quanto as entidades de ex-perseguidos políticos e seus familiares e, de forma individual os próprios ex-presos, serviam-se desse argumento para conseguir a abertura dos documentos. Ainda, não se pode esquecer que no cerne da reivindicação dessas entidades pelo amplo acesso aos arquivos militares está o esclarecimento das circunstâncias de diversas mortes e desaparecimentos do período de repressão, especialmente no que concerne ao local onde se encontram as ossadas dos desaparecidos políticos. Além, é claro, de esses arquivos contribuírem para uma reconstrução mais completa dos "anos de chumbo".

Nesse sentido, caminhou a Lei de Acesso à Informação (Lei no 12.527/2011): ampliar o acesso aos documentos públicos. Para tanto, restringiu para três os tipos de classificação dos documentos (foi retirado o grau de confidencial) e estabeleceu que os critérios para classificar e reclassificar as informaçôes devem ser os menos restritivos possíveis; reduziu os prazos máximos de sigilo, passando o nível mais alto de sigilo para vinte cinco anos, prorrogável por igual período e, transcorrido o prazo, a informação será automaticamente de acesso público. Em relação à negativa de acesso à documentação sob argumento de que a informação é parcialmente ou totalmente sigilosa, poderá o interessado interpor recurso à autoridade hierarquicamente superior a que denegou o acesso à informação, em caso de nova negativa, poderá recorrer à Controladoria Geral da União (CGU) e, em caso de violação do direito fundamental de acesso a informaçôes públicas, a lei estabeleceu responsabilização ao agente público ou militar, que poderáo responder por improbidade administrativa.

Essa lei também inseriu temas afetos aos documentos e informações produzidas durante o regime militar. São eles: os documentos que versarem sobre condutas, praticadas por agentes públicos ou a mando de autoridades públicas, que 
impliquem violação de direitos humanos, não podem ser objeto de qualquer restrição de acesso (art. 22, $\$$ único); o direito à vida privada náo poderá ser invocado para restrição dos documentos, quando as ações forem voltadas para recuperação de fatos históricos relevantes (art. 31, $\$ 4^{\circ}$ ) e, nos incisos do $\$ 3^{\circ}$ do art. 31, traz algumas exceçôes para dispensa do consentimento das pessoas citadas nos documentos.

Como se observa, o texto não se refere exatamente ao período dos anos de repressão política, mas seu conteúdo deixa entrever que essas disposiçóes visavam salvaguardar a abertura dos arquivos da ditadura, mormente diante da eminência da criaçáo por lei da Comissáo Nacional da Verdade, que tinha como finalidade esclarecer as graves violaçôes de direitos humanos praticadas durante a ditadura militar. Vale destacar alguns outros indícios que corroboram essa afirmação: (i) o PL 5228/2009, de autoria do Executivo apensado ao PL 219/2003, foi enviado para apreciação do Congresso Nacional após a edição do PNDH-3 (que continha em um dos seus eixos a criação da Comissão Nacional da Verdade); (ii) o projeto de lei que deu origem a CNV foi aprovado no Senado Federal um dia após essa mesma Casa congressual aprovar a LAI e (iii) essas duas leis foram sancionadas no mesmo dia, 18 de novembro de 2011. Ocasião em que a então Presidente da República, Dilma Rousseff (uma das ministras, à época, responsáveis pelo texto da Lei $\mathrm{n}^{\mathrm{o}}$ 12.527/2011), declarou: "O que era lei de sigilo se torna de lei acesso à informação. E nenhum ato ou documento que atente contra os direitos humanos poderá ser colocado sob sigilo. Essa é uma conexão decisiva com a lei que cria a Comissão da Verdade. Uma não existe sem a outra” (DISCURSO..., 2011).

Vale ressaltar que a aprovação da LAI ocorreu mesmo com os entraves encontrados no Senado Federal, como demonstrado, os parlamentares entraram em um acordo em relação ao texto da LAI e aprovaram a proposta sem maiores alterações. Aqui vale apontar o papel de destaque desempenhado pelo poder Executivo no que se refere a aprovação da LAI, importa destacar a atuação da presidente, à época, Dilma Rousseff.

Desde a época em que era ministra, Dilma buscava dar uma resposta àqueles que foram vítimas da ditadura, porém apenas conseguiu atender uma importante parte dessa demanda, que também era sua, quando eleita para presidente. É claro que não se pode levar em conta apenas sua atuação, existe todo um processo anterior de embates, que levou a edição da LAI, contudo, acredita-se que não fosse um ator em posição de destaque, favorável à abertura dos documentos, a assumir a presidência, provavelmente, como demonstraram os entraves ocasionados no Senado Federal, essa norma estaria ainda em discussão. 


\section{Conclusão}

Para Fico (2012), a demanda pela abertura dos arquivos da ditadura adquiriu caráter central no caso brasileiro, já que esses documentos servem a diversos propósitos, que vão desde elemento de prova para fundamentar os pedidos de reparaçóes pecuniárias pelas vítimas, até o auxílio na localização dos restos mortais dos desaparecidos políticos, especialmente aqueles que morreram durante a "Guerrilha do Araguaia". Ainda, segundo esse autor, essa documentação, além de permitir conhecer o modus operandi do aparelho repressivo estatal, fornece subsídios para reconstruir a história pelo olhar daqueles que se opunham ao regime autoritário, o que poderá auxiliar na superação de "equívocos, como o mito de que a ditadura brasileira não foi violenta".

De acordo com Fico (2012), os militares produziram uma gama enorme de documentos nos anos de repressão que, legitimados por instrumentos normativos draconianos em vigor até a edição da LAI, foram carimbados como sigilosos para impedir o conhecimento do seu conteúdo. Essa amnésia forçada e institucionalizada traz prejuízos à memória histórica, que tem papel fundamental para a construção da identidade de um povo.

Por se tratar a memória de um espaço de disputa política entre os atores históricos, a tensão entre esquecimento e memória é uma constante em suas relações de poder, que de um lado são permeadas pela persistente tentativa de impor institucionalmente o silêncio e do outro pela luta incansável contra essa amnésia imposta, sobretudo para se evitar o risco de repetição do passado (PADRÓS, 2009). Para esse autor, se no contexto discricionário o documento foi criado para justificar detençôes ou condenaçôes, em um democrático, ele pode "desempenhar um papel diametralmente oposto ao qual foi concebido. Feito para acusar e punir, sua posterior existência se torna prova que incrimina a violência estatal" (PADRÓS, 2009, p. 42).

A institucionalização de um silêncio oficial pretendeu, ao longo desses anos, censurar, acobertar, apagar as violações sistemáticas de direitos humanos praticadas no período de 1964 a 1985. O retorno à democracia, no caso do Brasil, não foi capaz de impedir que aqueles que se valeram do aparelho estatal, para reprimir de forma violenta os que eram contrários ao regime militar, novamente se utilizassem do Estado. Isso ocorreu, como visto, via poder Executivo, especialmente nos governos FHC e Lula, que produziram normas (decretos n $\mathrm{n}^{\circ}$ 4.553/2002 - BRASIL, 2002 - e no 5.584/2005 - BRASIL, 2005) favorecendo os ideais de silêncio, ocultamento e esquecimento. 
Como demonstrado o embate de forças para consecução de um dos pilares da Justiça de transição, qual seja, buscar a verdade e a afirmação da memória para garantir a não repetição das atrocidades, mostrou-se árduo, no caso brasileiro, para os que lutavam pela abertura dos arquivos. Prova disso é que foram necessários seis governos democráticos, para que uma mudança política relativa ao acesso à informação se consolidasse, o que ocorreu apenas em 2011 com a edição da LAI. Essa conquista, em conjunto com a reparação das vítimas de atos de exceção, ainda não constituem o ideal da justiça transacional, pois a atribuição de responsabilidades civis e criminais aos agentes estatais nunca se efetivou e, provavelmente náo ocorrerá, mas são passos importantes ao combate à "cultura do esquecimento" e para a construção de uma nova ordem democrática.

- Alessandra Guimarães Soares é Doutora em Ciência Política, pela Universidade Federal de São Carlos, e Pós-doutoranda em Direito, pela Universidade Nove de Julho. E-mail: aleguisoares@gmail.com.

\section{Referências}

ALENCAR, Kennedy. Esquerda Armada não é terrorista, diz Tarso. Folha de São Paulo, São Paulo, 05 nov. 2008. Disponível em: < http://www1.folha.uol.com.br/fsp/brasil/fc0511200811.htm>. Acesso em: 18 out. 2016.

ATO Coroa série de pressóes militares. Folha de São Paulo, São Paulo, 30 abr. de 2003. Disponível em: < http://www1.folha.uol.com.br/fsp/brasil/fc2004200311.htm>. Acesso em: 25 dez. 2016.

BAUMGARTNER, Frank R; JONES, Bryan D. Agendas and Instability in American Politics. Chicago, University of Chicago Press, 1993.

BRASIL. Constituição (1988). Constituição da República Federativa do Brasil de 1988. Disponível em: <http://www.planalto.gov.br/ccivil_03/constituicao/constituicao.htm>. Acesso em: 17 fev. 2016.

BRASIL. Decreto Lei no 2.134/1997. Regulamenta o art. 23 da Lei no 8.159, de 8 de janeiro de 1991, que dispóe sobre a categoria dos documentos públicos sigilosos e dá outras providências. Diário Oficial da União, DF, 27 de janeiro de 1997. Disponível em: < http://www.planalto.gov.br/ccivil_03/decreto/d2134.htm>. Acesso em: 13 jun. 2017.

BRASIL. Decreto Lei no 5.301/2004. Regulamenta o disposto na Medida Provisória no 228, de 9 de dezembro de 2004 e dá outras providências. Diário Oficial da União, DF, 09 de dezembro de 2004. 
Disponível em: < http:/www.planalto.gov.br/ccivil_03/_ato2004-2006/2004/decreto/D5301.htm>. Acesso em: 25 abril 2016.

BRASIL. Decreto Lei no 5.584/2005. Dispóe sobre o recolhimento ao Arquivo Nacional dos documentos arquivísticos públicos e dá outras providências. Diário Oficial da União, DF, 18 de novembro de 2005. Disponível em:<http:/www.planalto.gov.br/ccivil_03/_Ato20042006/2005/Decreto/D5584.htm>. Acesso em: 14 jun. 2017.

BRASIL. Diário da Câmara dos Deputados. Brasília, 14 abril 2010. Disponível em: < http://www.camara.leg.br/internet/sitaqweb/TextoHTML.asp?etapa=3\&nuSessao=073.4.53.O\&nu Quarto $=8 \&$ nuOrador $=2 \&$ nuInsercao $=0 \&$ dtHorarioQuarto $=20: 16 \&$ sgFaseSessao $=O D \% 20 \% 20 \% 2$ 0\%20\%20\%20\%20\%20\&Data=13/04/2010\&txApelido=REGINALDO\%20LOPES\#> Acesso em: 27 jan. 2016.

BRASIL. Diário do Senado Federal. Brasília, 26 de outubro de 2010

BRASIL. Lei no 8.112 de 11 de dezembro de 1990. Regula o acesso a informação e dá outras providências. Diário Oficial da União, DF, 12 de dezembro de 1990. Disponível em: <http://www.planalto.gov.br/ccivil_03/LEIS/L8112cons.htm>. Acesso em: 27 jun. 2017.

BRASIL. Lei no 8.159 de 08 de janeiro de 1991. Dispóe sobre a política nacional de arquivos públicos e privados e dá outras providências. Diário Oficial da União, DF, 09 de janeiro de 1991. Disponível em: <http://www.planalto.gov.br/ccivil_03/LEIS/L8159.htm\#art23>. Acesso em: 22 jun. 2017.

BRASIL. Lei no 4.553 de 27 de dezembro de 2002. Dispóe sobre a salvaguarda de dados, informaçóes, documentos e materiais sigilosos e dá outras providências. Diário Oficial da União, DF, 14 de dezembro de $2002 . \quad$ Disponível em: <http://www.planalto.gov.br/ccivil_03/decreto/2002/D4553.htm\#art69>. Acesso em: 27 jun. 2017.

BRASIL. Lei $n^{\circ} 11.111$ de 05 de maio de 2005. Regulamenta a parte final do disposto no inciso XXXIII do caput do art. $5^{\circ}$ da Constituição Federal e dá outras providências. Diário Oficial da União, DF, 06 de maio de 2005. Disponível em: <http://www.planalto.gov.br/ccivil_03/_ato20042006/2005/lei/l11111.html>. Acesso em: 27 jun. 2017.

BRASIL. Lei no 12.528 de 18 de novembro de 2011a. Cria a Comissão Nacional da Verdade no âmbito da Casa Civil da Presidência da República. Diário Oficial da União, DF, 18 de novembro de 2011. Disponível em: <http://www.planalto.gov.br/ccivil_03/_ato20112014/2011/lei/112528.html> Acesso em: 30 jun. 2017.

BRASIL. Lei $n^{\circ} 12.527$ de 18 de novembro de 2011 b. Regula o acesso a informação e dá outras providências. Diário Oficial da União, DF, 18 de novembro de 2011. Disponível em: <http://www.planalto.gov.br/ccivil_03/_ato2011-2014/2011/lei/l12527.html>. Acesso em: 28 jun. 2017.

DISCURSO da Presidenta da República, Dilma Rousseff, durante cerimônia de sanção do projeto de Lei que garante o acesso a informaçóes públicas e do projeto de Lei que cria a Comissão Nacional da Verdade. Portal do Planalto, Palácio do Planalto, Brasília, 18 nov. 2011. Disponível em: <http://www2.planalto.gov.br/acompanhe-o-planalto/discursos/discursos-da-presidenta>. Acesso em: 12 out. 2015.

FARIA, Thiago. Punição de torturador honra a biografia de Lula, diz ministro. Folha de São Paulo, São Paulo, 02 dez. 2008. Disponível em: < http://www1.folha.uol.com.br/fsp/brasil/fc0212200812.htm>. Acesso em: 15 out. 2016. 
FICO, Jorge. História do Tempo Presente, eventos traumáticos e documentos sensíveis: o caso brasileiro. Varia Historia, Belo Horizonte, v. 28, n. 47, p. 43-59, 2012.

FISHER, Frank; FORESTER, John. The Argumentative Turn in Policy Analysis and Planning. London: Duke University Press, 1993.

JOFFILY, Mariana. Direito à informação e direito à vida privada: os impasses em torno do acesso aos arquivos da ditadura militar brasileira. Estudos Históricos, Rio de Janeiro, v. 25, n. 49, p. 129-148, 2012 Disponível em: <http://bibliotecadigital.fgv.br/ojs/index.php/reh/article/view/3766>. Acesso em: 14 de jan. 2016.

JOHN, Peter. Analysing Public Policy. London: Cassell, 1988.

JOHN, Peter. Is There Life After Policy Streams, Advocacy Coalitions, and Punctuations: Using Evolutionary Theory to Explain Policy Change? Policy Studies Journal, Medford, v. 31, n. 4, p. 481-498, nov. 2003. Disponível em: <http://onlinelibrary.wiley.com/doi/10.1111/15410072.00039/full>. Acesso em: 13 out. 2016.

KINGDON, John. Agendas, Alternatives, and Public Policies. 3a. Ed. New York: Harper Collins, 2003.

KRAKOVICS, Fernanda; ALENCAR, Kennedy. Governo quer abrir arquivos sigilosos, mas "sem pressa”. Folha de São Paulo, 27 de outubro de 2004. Disponível em: <http://www1.folha.uol.com.br/fsp/brasil/fc2710200402.htm>. Acesso em: 05 abr. 2016.

LOPES, Reginaldo. Projeto de lei da Câmara no 219, de 2003. Regulamenta o inciso XXXIII do art. $5^{\circ}$ da Constituição Federal e dá outras providências (Dispóe sobre prestação de informações detidas pelos órgãos da Administração Pública). Disponível em: <http://www.camara.gov.br/proposicoesWeb/fichadetramitacao?idProposicao=105237>. Acesso em: 15 fev. 2016.

MAGALHÃES, Mario. Lula mantém sigilo "eterno" de documentos. Folha de São Paulo, São Paulo, 20 abril 2003. Disponível em: <http://www1.folha.uol.com.br/fsp/brasil/fc2004200310.htm>. Acesso em: 05 abr. 2016.

MAGALHÁES, Mário. Lula critica Pinochet, mas veta arquivos da ditadura. Folha de São Paulo, São Paulo, 12 dez. 2006. Disponível em: < http://www1.folha.uol.com.br/folha/brasil/ult96u87640.shtml> Acesso em: 05 abr. 2016.

OLIVERIA, Marcelo. MPF pede acesso a documentos secretos da ditadura. Procuradoria da República em São Paulo, São Paulo. 21 dez. 2005. Disponível em: <http://www.prsp.mpf.mp.br/sala-deimprensa/noticias_prsp/noticia-2586>.Acesso em: 05 out. 2015.

OLIVEIRA, Sônia Maria Leite de. Internalização do regime internacional dos direitos humanos pósConferência de Viena, em 1993: o caso brasileiro. 2012. 92 f. Dissertação (Mestrado em Ciências Sociais) - Faculdade de Filosofia e Ciências Humanas, Pontifícia Universidade Católica do Rio Grande do Sul, Porto Alegre. 2012.

PADRÓS, Enrique Serra. História do tempo presente, ditaduras de segurança nacional e arquivos repressivos. Tempo e Argumento, Florianópolis, v. 1, n. 1, p. 30-45, jan-jun. 2009. Disponível em: <http://www.revistas.udesc.br/index.php/tempo/article/view/708>. Acesso em: 10 set. 2016.

SABATIER, Paul A. An Advocacy Coalition Model of Policy Change and the Role of Policy-Oriented Learning Therein, Policy Sciences, New York, v. 21, n. 2/3, p. 129-168, 1988. Disponível em: https://www.jstor.org/stable/4532139. Acesso em: 24 de mai. 2016. 
PODER EXECUTIVO. Projeto de lei da Câmara no 5.228, de 2009. Regula o acesso a informaçóes previsto no inciso XXXIII do art. $5^{\circ}$, inciso II do $\$ 3^{\circ}$ do art. 37 e no $\$ 2^{\circ}$ do art. 216 da Constituição, e dá outras providências. (Dispóe sobre o acesso pleno, imediato e gratuito a informaçóes públicas e estabelece critérios para proteção das informaçóes pessoais e sigilosas. _ Altera a Lei $\mathrm{n}^{\circ}$ 8.112, de 1990, para isentar o servidor de ser responsabilizado civil, penal ou administrativamente por dar ciência a autoridade competente de informaçóes concernentes à prática de crime ou improbidade. Revoga a Lei $n^{\circ} 11.111$, de 2005 e os arts. 22 a 24 da Lei $n^{\circ} 8.159$, de 1991. Regulamenta a Constituição Federal de 1988). Disponível em: <http://www.camara.gov.br/proposicoesWeb/fichadetramitacao?idProposicao=434566>; Acesso em: 20 fev. 2016.

PROJETO quer revogar decreto. Folha de São Paulo, São Paulo, 08 fev. 2004. Disponível em: <http://www1.folha.uol.com.br/fsp/brasil/fc0802200421.htm>. Acesso em 04 fev. 2016.

SABATIER, Paul A.; JENKINS-SMITH, Hank C. Policy Change and learning: the advocacy coalition approach. Boulder: Westview Press, 1993.

SABATIER, Paul A.; JENKINS-SMITH, Hank C. The advocacy coalition framework: An assessment. In SABATIER, Paul A. (Ed.). Theories of the Policy Process. Boulder: Westview Press, 1999.

SABATIER, Paul A.; ZAFONTE, Matthew. Are Bureaucrats and Scientists Members of Advocacy Coalitions? Evidence from an Intergovernmental Water Policy Subsystem. In: SABATIER, Paul A. (Ed.). An Advocacy Coalition Lens on Environmental Policy. Cambridge: MIT Press, 2004.

SABATIER, Paul A.; WEIBLE, Christopher M. The advocacy coalition framework: innovations and clarifications. In: SABATIER, Paul A. (Ed.) Theories of the policy process. Boulder: Westview Press, 2007.

SILVA, Shirley Linny da; FROTA, Maria Guiomar da Cunha. A questão do acesso aos arquivos do Departamento de Ordem Política e Social do Estado de Minas Gerais numa abordagem multidimensional. Perspectivas em Ciência da Informação, Belo Horizonte, v. 14, número especial, p. 105-119, 2009. Disponível em: <http://www.scielo.br/scielo.php?script=sci_arttext\&pid=S141399362009000400008\&lng=pt\&nrm=iso\&tlng=pt>. Acesso em: 02 fev. 2016.

TELES, Janaína de Almeida. A abertura dos arquivos da ditadura militar e a luta dos familiares de mortos e desaparecidos políticos no Brasil. 2006. Disponível em: <http://diversitas.fflch.usp.br/files/a\%20abertura\%20dos\%20arquivos\%20da\%20ditadura.pdf>. Acesso em: 29 nov. 2016.

VIANA, Luna Bouzada Flores. Entre o abstrato e o concreto: legados do embate sobre o Projeto de Integração do São Francisco ou da transposição. 2011. 200 f. Dissertação (Mestrado em Ciência Política) - Programa de Pós-Gradução em Ciência Política, Universidade de Brasília, Brasília. 2011.

VICENTE, Victor Manuel Barbosa. Análise de mudanças institucionais na política de ordenamento territorial urbano no Distrito Federal (1991-2009). 2012. 246 f. Tese (Doutorado em Administração) - Programa de Pós-Graduação em Administração, Universidade de Brasília, Brasília, 2012.

ZAVERUCHA, Jorge. A fragilidade do Ministério da Defesa Brasileiro. Revisa de Sociologia e Política, Curitiba, 25, p. 107-121, nov. 2005. Disponível em: <.http://www.scielo.br/scielo.php?script=sci_arttext\&pid=S0104-44782005000200009>. Acesso em: 14 mar. 2016. 
196 | Alessandra Guimarães Soares

WEIBLE, Cristopher M.; SABATIER, Paul A.; JENKINS-SMITH, Hank C.; NOHRSTEDT, Daniel; HENRY, Adam Douglas; DELEON, Peter. A quarter century of the advocacy coalition framework an introduction to the special issue. Policy Studies Journal, Medford, MA, v. 39, n. 3, p. 349-360, 2011.

Texto recebido em 10 de julho de 2017. Aprovado em 21 de julho de 2017. 